\title{
ANÁLISIS DE LA PROTESTA DIGITAL \#NOSOTRASTENEMOSOTROSDATOS EN TWITTER DURANTE LA PANDEMIA DE LA COVID-19
}

\section{ANALYSIS OF THE DIGITAL PROTEST \#NOSOTRASTENEMOSOTROSDATOS ON TWITTER DURING THE COVID-19 PANDEMIC}

\author{
Lidia Ángeles García González \\ Universidad de Guanajuato, México \\ (iD) https://orcid.org/0000-0001-9363-5280
}

Autor para correspondencia: Lidia Ángeles García González, email: la.garciagonzalez@ugto.mx

\section{Resumen}

El presente estudio consiste en un análisis de corte cuantitativo, que utilizó la aplicación de Google llamada Twitter Archiver, mediante el análisis de contenido de 5,000 tuits que usaron el hashtag \#NosotrasTenemosOtrosDatos en el contexto de la pandemia de la COVID-19 en la red social de Twitter. El objetivo principal de este artículo es analizar las temáticas y debates suscitados en Twitter a raíz del uso de este hashtag. Los principales hallazgos dan cuenta de un renovado repertorio de acción colectiva en el espacio digital y las demandas mediante el feminismo hashtag. Los resultados muestran una diversidad de temas en la conversación digital generada a través de diversas cuentas de Twitter por parte de colectivas feministas, actrices, influencers, periodistas, actores políticos, OSCs, etc.; enfocándose particularmente en la visibilización del incremento de la violencia contra las mujeres en el contexto de la pandemia de la COVID-19 en México, ante la negación del discurso presidencial sobre el incremento de las llamadas al 911 por violencia de género, que estigmatizó las demandas feministas por una vida libre de violencia contra las mujeres mexicanas, así como una creciente polarización política debido a la presencia de diversos actores políticos entrelazados en la protesta digital feminista.

Palabras clave: acción colectiva, sitios de redes sociales (SNSs), activismo digital feminista, Twitter, feminismo hashtag.

\begin{abstract}
This study consists of a quantitative analysis, using the Google application called Twitter Archiver, by analyzing the content of 5,000 tweets that used the hashtag \#NosotrasTenemosOtrosDatos in the context of the COVID-19 pandemic on the Twitter social network. The main objective of this article is to analyze the issues and debates raised on Twitter because of the use of this hashtag. The main findings show a renewed repertoire of collective
\end{abstract}


action in the digital space and demands through the feminist hashtag. The results show a diversity of topics in the digital conversation generated through diverse Twitter accounts by feminist collectives, actresses, influencers, journalists, political actors, ONGs, etc. focusing particularly on the visibility of the increase of violence against women in the context of the COVID-19 pandemic in Mexico, in the face of the denial of the presidential discourse on the increase of 911 calls for gender violence, which stigmatized feminist demands for a life free of violence against Mexican women, as well as a growing political polarization due to the presence of various political actors intertwined in the feminist digital protest.

Keywords: collective action, social network sites (SNSs), digital feminist activism, Twitter, hashtag feminism.

Recibido: 16/08/2021

Aceptado: 01/11/2021

\section{Introducción}

El 6 de mayo de 2020, en la conferencia matutina del presidente de México, Andrés Manuel López Obrador, al ser cuestionado por una mujer periodista sobre cómo ha evaluado el gobierno la violencia contra las mujeres, así como su incremento en los hogares familiares durante el confinamiento por la pandemia de la COVID-19, expresó lo siguiente: “en el caso de la violencia contra las mujeres no hemos nosotros advertido un incremento desde luego la forma de medirlo son las denuncias que se presentan, puede haber cifras negras, pero en las denuncias no ha habido un incremento" (Centro de Producción de Programas Informativos y Especiales [CEPROPIE], 2020b), argumentando que México cuenta con una cultura de "mucha fraternidad" en la familia, a diferencia de otros países.

Sin embargo, en lo referente a las llamadas de emergencia relacionadas con incidentes de violencia contra las mujeres, se dio un incremento durante el mes de marzo con un total de 26,171 llamadas (Badillo, 2020), lo que significa un incremento de $20.45 \%$ comparado con febrero de 2020, cuando se recibieron 21,727 llamadas, y de $60 \%$ respecto de marzo de 2019, cuando fueron 16,289, según las cifras del Secretariado Ejecutivo del Sistema Nacional de Seguridad Pública (2020). Asimismo, el mes de abril de 2020 fue considerado el más violento para las mujeres en México; en términos de feminicidios se registraron 359 muertes violentas, lo cual se traduce en más de 11 feminicidios al día.

Como respuesta ante los comentarios del presidente Andrés Manuel López Obrador, un grupo de académicas, activistas, legisladoras y organizaciones de la sociedad civil realizaron una carta en la plataforma Google Docs que alcanzó más de 7,000 firmas (Reyes, 2020), en donde se expresa la indignación frente a las declaraciones del presidente en torno a la violencia contra las mujeres 
dentro del seno familiar y el confinamiento debido a la pandemia de la COVID-19, situando en el centro esta problemática.

El 11 de mayo de 2020, comenzó a circular el video "Presidente López Obrador, Nosotras Tenemos Otros Datos" (Nosotras Tenemos Otros Datos [NTOD], 2020a), realizado por la red de organizaciones feministas Nosotras Tenemos Otros Datos, que surge en 2020 con representación en toda la República Mexicana, y quienes han realizado un esfuerzo colectivo a raíz: "de la ausencia de respuestas por parte del Estado Mexicano hacia la violencia y discriminación que viven las mujeres y niñas, y en demanda del cumplimiento de nuestros derechos y del acceso a la justicia para las víctimas" (NTOD, 2020a, p. 2), siendo 44 mujeres activistas, académicas, legisladoras y artistas. Algunas de las organizaciones que participaron en esta iniciativa fueron la Red Nacional de Refugios (RNR), la Coalición contra el Tráfico de Mujeres y Niñas en América Latina y el Caribe, Católicas por el Derecho a Decidir, Renaser y Mujeres Alas (Xantomila, 2020), por mencionar algunas.

Es importante mencionar que, con anterioridad, el 24 de marzo de 2020, en la conferencia matutina del ejecutivo nacional ante la fase 2 de la pandemia de la COVID-19, afirmó que generalmente son las mujeres las que cuidan de los padres, pues lo hombres pueden ser más desprendidos; sin embargo, hizo un llamado tanto a hombres como a mujeres a cuidar de los ancianos que son el grupo más vulnerable ante la pandemia (Milenio, 2020). Estas declaraciones generaron reacciones diversas en las redes sociodigitales en donde lo acusaron de sexista y misógino.

Diversos actores políticos y algunos periodistas opositores al gobierno del presidente Andrés Manuel López Obrador han tomado una aparente postura pro-feminista; el asunto ha sido "aprovechado por los políticos quienes han intentado colgarse del tema, a pesar de que ellos mismos han impedido avances en la lucha feminista, como el derecho al aborto seguro" (Jasso, 2020). Esto supone una creciente polarización en los entornos digitales que se presenta como un fenómeno alarmante y preocupante en las sociedades democráticas, ya que se produce cuando los miembros de un grupo que delibera se mueven hacia un punto más extremo en la dirección indicada predeliberadamente por una tendencia de sus miembros (Sunstein, 2002); es decir, este tipo de oportunismo por parte de los actores políticos corresponde a un fenómeno que rebasa a la polarización.

Los intercambios políticos en las redes sociodigitales suelen ser negativos y también se pueden manifestar comportamientos incívicos que son característicamente groseros y descorteses, mostrando una falta de consideración hacia las demás personas, lo que contribuye al aumento de la polarización afectiva. En este sentido, la polarización de élite puede aumentar la polarización política de masas (Abramowitz \& Saunders, 2008; Hetherington, 2001) y esto se puede apreciar con relación al activismo digital feminista. Autores como Bakshy et al. (2015) y Theocharis et al. (2020) encuentran que las y los usuarios de Facebook y Twitter se exponen a un nivel sorprendentemente alto 
de diversidad de opiniones, como es el caso de análisis del presente estudio a partir del hashtag en Twitter \#NosotrasTenemosOtrosDatos.

Finalmente, una de las posturas que causó más controversia entre las colectivas feministas por parte de las declaraciones del ejecutivo nacional se dio unas semanas antes, previo a la contingencia sanitaria de la pandemia de la COVID-19, cuando el 14 y 15 de febrero de 2020, las colectivas feministas llevaron a cabo en la Ciudad de México y en otras ciudades del país, una serie de protestas para exigir justicia por el feminicidio de Ingrid Escamilla, ocurrido el 9 de febrero de 2020 en la alcaldía Gustavo A. Madero, a manos de su pareja sentimental. Al mismo tiempo, se suscitaron las exigencias de justicia por el feminicidio de la niña Fátima de 7 años, cuyo cuerpo fue encontrado en la alcaldía Tláhuac. Las palabras textuales del presidente fueron: "Le pido a las feministas, con todo respeto, que no nos pinten las puertas, las paredes. (Les digo) que estamos trabajando para que no haya feminicidios, que no somos simuladores, y que no esperen que nosotros actuemos como represores, que no nos confundan; sabemos, porque llevamos años luchando, cómo sacarle la vuelta a la provocación" (CEPROPIE, 2020a).

En tal sentido, las declaraciones del ejecutivo federal en contra de las mujeres activistas respecto a las manifestaciones que han tenido lugar en los últimos meses, la negación de la violencia contra las mujeres y niñas, y el recorte presupuestal en el Instituto Nacional de las Mujeres -órgano dependiente de la Secretaría de Gobernación que aprobó una reducción a su presupuesto del 75\%,
151.9 millones de pesos (Salazar Méndez, 2020)-, han sido motivos de gran indignación entre diversas colectivas feministas, quienes han alzado la voz para exigir un cambio en la política pública para prevención y atención a la creciente problemática de la violencia contra las mujeres y niñas.

En consecuencia, el presente estudio exploratorio tiene como objetivo conocer y realizar un análisis sobre la protesta digital feminista en Twitter, a partir del hashtag \#NosotrasTenemosOtrosDatos durante la pandemia de la COVID-19, así como sobre la diversidad de temáticas que surgen en el activismo digital feminista. Las preguntas de esta investigación versan acerca de conocer: ¿qué temáticas giran en torno al hashtag de la colectiva feminista \#NostrasTenemosOtrosDatos en Twitter?, ¿quiénes fueron las principales tuiteras o tuiteros que utilizaron el hashtag \#NosotrasTenemosOtrosDatos?, ¿cuáles fueron los principales tuits y las temáticas más re-tuiteadas por las y los usuarios de Twitter en torno al hashtag \#NosotrasTenemosOtrosDatos?, ¿qué medios digitales publicaron notas periodísticas en torno al hashtag \#NosotrasTenemosOtrosDatos?

\section{La acción colectiva feminista en el contexto de las redes sociodigitales}

En los últimos años, hemos presenciado algunos de los más representativos ejemplos de la lucha feminista actual en un contexto de redes 
sociodigitales, jugando un papel fundamental en el quehacer del activismo digital feminista a partir de que le ha provisto de mayor participación en la agenda pública y un lenguaje propio (Piñeiro-Otero, 2021).

Si bien, una de las conceptualizaciones sobre las potencialidades de los movimientos sociales desde la perspectiva de Castells para la acción colectiva es lo que él denomina el "proceso de comunicación autónoma" (2012), que través de Internet en el contexto de la sociedad red, se define como un proceso de comunicación que implica independencia de los canales de los medios de comunicación tradicionales y de los de gobiernos, así como la oportunidad de comunicar abiertamente sin restricciones a un público más amplio a través de las redes sociodigitales. En este escenario, en el contexto de la pandemia por la COVID-19, la colectiva feminista Nosotros Tenemos Otros Datos se vio en la posibilidad, mediante la acción colectiva, de lanzar a través de Twitter con el uso del hashtag \#NosotrasTenemosOtrosDatos una narrativa que dio visibilidad al incremento de la violencia contra las mujeres durante la contingencia sanitaria.

Un elemento específico que caracteriza a este tipo de acción colectiva reside en que son "movimientos altamente auto-reflexivos" (Castells, 2012), frecuentemente se auto-examinan como grupos e individuos acerca de lo que están buscando cambiar y lograr. Las tecnologías de información y comunicación (TIC) brindan a las y los activistas nuevas oportunidades como "las redes de información que no son fácilmente controlables por el estado y herramientas de coordinación [...] que pueden estar incorporadas en redes confiables de familia y amigos" (Howard \& Hussain, 2010, p. 10).

Dentro de las potencialidades de las prácticas comunicativas a través de Internet de las y los activistas es que han permitido un nivel de autoreflexión que ha posibilitado la creación de puntos de vista alternativos, resistiendo los discursos que imponen los medios tradicionales y los discursos dominantes (Mattoni et al., 2010). En otras palabras, las redes sociodigitales tienen el potencial de reconfigurar las relaciones del poder comunicativo, desafiando el control monopólico de los medios de comunicación, producción y difusión por parte de instituciones estatales y comerciales (Etling et al., 2010; Loader \& Mercea, 2011). Otra transformación relevante de la organización de los movimientos sociales es que las "narrativas de identidad personal”, están reemplazando a los "guiones sociales colectivos" y a las identidades de grupo como centro de la organización social (Poell \& Borra, 2011).

Una de las formas más conocidas de promover la acción colectiva en los espacios en línea, según Van Laer (2007), es a través de la publicación de informes, fotografías o vídeo en línea, por el cual "una nueva gama de personas puede compartir la emoción en el período previo a una acción o después de que se haya producido un evento de protesta como resultado del cual se puede desarrollar apoyo" (p. 7).

En México, días después de la marcha feminista \#8M y el \#9M en 2020, se dio el confinamiento en el país debido a la pandemia por COVID-19, la cual obstaculizó la continuidad del movimiento en el espacio público. Sin embargo, con otras dinámicas en las redes sociales de Internet: 
"esto deja ver que la potencia del movimiento se mantiene activa" (Álvarez Enríquez, 2020, p. 170). El movimiento feminista en México durante el gobierno del presidente Andrés Manuel López Obrador, ha sido una oposición auténtica y legítima "por su capacidad de cuestionar la actuación e indiferencia de la actual administración que prometía cambios estructurales y mayor respeto a los derechos humanos de toda la población" (Cerva-Cerna, 2021, p. 123). En consecuencia, la acción colectiva en el contexto de las redes sociodigitales, se ha convertido en un fenómeno comunicativo de reciente estudio a raíz del activismo digital feminista y lo que actualmente se denomina feminismo hashtag que a continuación examinaremos.

\section{Activismo digital feminista y feminismo hashtag}

Los diferentes tipos de prácticas feministas digitales permiten formas específicas de potencialidades para la acción colectiva, que incluyen sentimientos de conexión, comprensión compartida, seguridad y resolución. De esta manera, la forma en que los espacios digitales habilitan diferentes capacidades depende del tipo de plataforma digital (Mendes et al., 2019).

También podemos ver cómo las redes sociodigitales permiten la consolidación de experiencias grupales de feminismo a través de feministas que utilizan Twitter y funciones de chat para comunicarse y desarrollar sus puntos de vista feministas más allá de los espacios materiales de la escuela, e incluso operan una cuenta conjunta de Twitter que crea una identidad digital colectiva
(Mendes, et. al. 2019). El feminismo digital tiene a muchas defensoras y defensores que promueven la influencia y el poder que brindan los medios sociales como herramienta política para difundir información y llevar el feminismo a las masas, es decir, a la democratización del feminismo.

Actualmente, las redes sociodigitales han tenido un gran efecto en el feminismo, dando paso a nuevas formas de organización y acción política, siendo una de las características del movimiento feminista (Muñoz-Saavedra, 2019), como afirman Pedraza \& Rodríguez (2019): “lo que caracteriza esta nueva forma de levantamiento es la posibilidad de conectar los diferentes espacios, esfuerzos y recursos con una visibilidad inédita" (p. 98).

Para Binder (2019), las ciberfeministas latinoamericanas ante su posicionamiento político de acción les exige una "actitud transformadora como una tarea de creación de imaginarios radicales y utopías que marquen la orientación de ese cambio" (p. 227). Las posibilidades que han dado ventaja a estos movimientos feministas, les ha proporcionado la creación de redes más horizontales, caracterizadas por su pluralidad y diversidad, haciendo posible su visibilidad tanto en su búsqueda de justicia como en la agenda política de género (Magaña García, 2019).

Ha sido a través del uso de "hashtags, lemas, redes organizativas, convocatorias internacionales, performances y vídeos se incorporan como herramientas novedosas al repertorio de los movimientos de mujeres en América" (Revilla Blanco, 2019, p. 48) que se han convertido en parte esencial de la protesta contra la violencia hacia las mujeres. En este sentido, surge el concepto 
denominado "feminismo hashtag" (Clark-Parsons, 2019) que ha sido definido como:

un tipo de actuación polémica que permite a los activistas politizar el personal, un objetivo de larga data de los movimientos feministas en los Estados Unidos, haciéndolo visible \#MeToo que agregó historias personales en una campaña de visibilidad en red, ilustrando la naturaleza sistémica de la violencia sexual” (p. 2).

Asimismo, la autora menciona que algunos estudiosos encuadran este tipo de activismo feminista como una práctica poderosa en la "política de la visibilidad", una forma de activismo centrado en cambiar la forma en que representamos, interpretamos y respondemos a las injusticias sociales a través de actuaciones públicas, pero también la crítica radical que, como poderosa táctica empleada para amplificar la conciencia el "feminismo hashtag", puede ser una forma de activismo que comienza y termina con la actuación y hace poco por transformar las estructuras de desigualdad.

Recientemente se ha publicado literatura académica de trabajos sobre Twitter y violencia de género contra las mujeres, así como de fenómenos asociados a la misoginia digital conocidos como el "troleo de género" o "troleo antifeminista en la plataforma Twitter" (Villar Aguilés \& Pecourt Gracia, 2021), a partir del análisis de contenidos de \#STOPfeminazis para llevar a cabo una ofensiva general contra el movimiento feminista. Asimismo, el estudio de Puente et al. (2021), a propósito del movimiento feminista del 8 de marzo de 2017 en España (8M), en donde el análisis de tuits, retuits y menciones de los hashtags más utilizados en este contexto como \#8M y \#NiUnaMenos, demostró la oportunidad que el testimonio sobre la violencia de género ofrece al activismo feminista digital para actuar de manera efectiva y política en Twitter, sorteando la invisibilidad y dando cuenta de que estos hashtags no forman comunidades conversacionales fuertes, sino que sirven para difundir mensajes a escala masiva.

Bernárdez Rodal et al. (2021) analizan la difusión de tuits críticos de uno de los fallos judiciales más controvertidos y extensamente publicitados en la historia española, que determinó que un grupo de hombres eran culpables de abuso, en lugar del delito de violación más grave. En 2018, estas autoras analizaron 73,904 tuits y concluyeron que Twitter es reconocido como la red social para expresar indignación política, además que las protestas sociales en la red están asociadas con procesos de militancia y movimiento feminista.

Cerva Cerna (2020), explica que desde una visión histórica el movimiento feminista no ha presentado significativos cambios en sus demandas, es decir, se caracteriza por ser revolucionaria porque se ubica como central la exigencia y la visibilización de una realidad que está naturalizada, siendo las mujeres las más perjudicadas. La autora acuña el término "la doble indignación" que se define como:

frente a un acontecimiento de violencia feminicidio, violencia sexual, desapariciones 
de mujeres-, la protesta emerge no sólo por el hecho en símismo, que en lo sustantivo se constituye en el primer agravio, el reclamo se extiende y profundiza a partir de un segundo momento de malestar colectivo que se produce por la forma en que las autoridades responden al primer agravio ( $p$. 182).

En particular, la autora señala que la actual administración de Andrés Manuel López Obrador se ha caracterizado por la "reproducción de estereotipos con una fuerte carga de machismo" (Cerva Cerna, 2020, p. 123).

\section{Metodología}

Para fines de este estudio, se utilizó la aplicación de Google llamada Twitter Archiver, que da la posibilidad de crear una herramienta archivadora de tuits usando hojas de cálculo de Google Drive. Esta herramienta guarda automáticamente todos los tuits de cualquier hashtag de Twitter o términos de búsqueda en una hoja de cálculo. En el presente estudio, se recolectaron 5,000 tuits del 6 de mayo al 18 de julio de 2020, que conforman el corpus de este análisis. El principal criterio para establecer el periodo de análisis con los tuits recolectados consistió en que el hashtag \#NosotrasTenemosOtrosDatos fuese incluido dentro del tuit publicado; desde la fecha del lanzamiento del hashtag comenzamos la búsqueda y descarga de tuits hasta la mitad del mes de julio, periodo en que se utilizó este hashtag que ha sido el objeto de estudio en el presente artículo.

Es primordial mencionar que la herramienta Twitter Archiver recolectó en una hoja de cálculo de Excel de Google Drive información acerca de la fecha en que fue publicado el tuit, el ID de la tuitera(o), la procedencia geográfica, el número de re-tuits que tuvo y el tuit publicado, el contenido del tuit cuando se trató de una nota periodística para analizar las temáticas sobre las cuales se publicaron en medios digitales (Imagen 1).

Asimismo, sobre los límites del presente análisis de contenido es relevante mencionar que el universo de tuits recolectados muestran los saberes de las tuiteras y tuiteros basándose solo en los tuits que publicaron, sin ahondar en un análisis de redes sobre la totalidad de discusiones orgánicas originadas y en donde haría falta explorar sobre las subjetividades de las tuiteras y tuiteros con otras herramientas metodológicas, como pueden ser la entrevista cualitativa, el análisis del discurso o el análisis visual sobre los mensajes publicados que utilizaron el hashtag \#NosotrasTenemosOtrosDatos.

En este sentido, en el presente estudio empleamos el análisis de contenido que, según López (2002, citando a Berelson, 1952), es una herramienta metodológica para el estudio y análisis de la comunicación de forma objetiva, sistemática y cuantitativa. Sobre las categorías de clasificación de las temáticas, se establecieron acorde al contenido de cada tuit o retuit en un documento de Excel, donde fueron registrados y en cada uno se estableció la temática conforme a su contenido, es decir, las 
categorías no fueron pre-establecidas, considerando como marco conceptual el activismo digital feminista y la polarización en las redes sociodigitales.

Por su parte, Krippendorff (1982) amplía la definición del análisis de contenido a una técnica de investigación para hacer inferencias válidas $\mathrm{y}$ confiables de datos con respecto a su contexto. La finalidad del análisis de contenido es crear datos que sean objetivos (centrados en la verdad), susceptibles de medición y tratamiento cuantitativo o cualitativo, así como significativos o explicativos de un hecho. Según Bardin (2002), el análisis de contenido es definido como un conjunto de técnicas de análisis de comunicaciones que utilizan procedimientos sistemáticos y objetivos de descripción del contenido de los mensajes. Para Krippendorff (1980), el análisis de contenido está calificado como una de las metodologías más significativas de la investigación sobre comunicación; es decir, su objetivo radica en estudiar de forma rigurosa y sistemática la naturaleza de los diferentes mensajes que se intercambian en los actos de comunicación que realizamos.

\section{Imagen 1}

Base de datos de Twitter Archiver

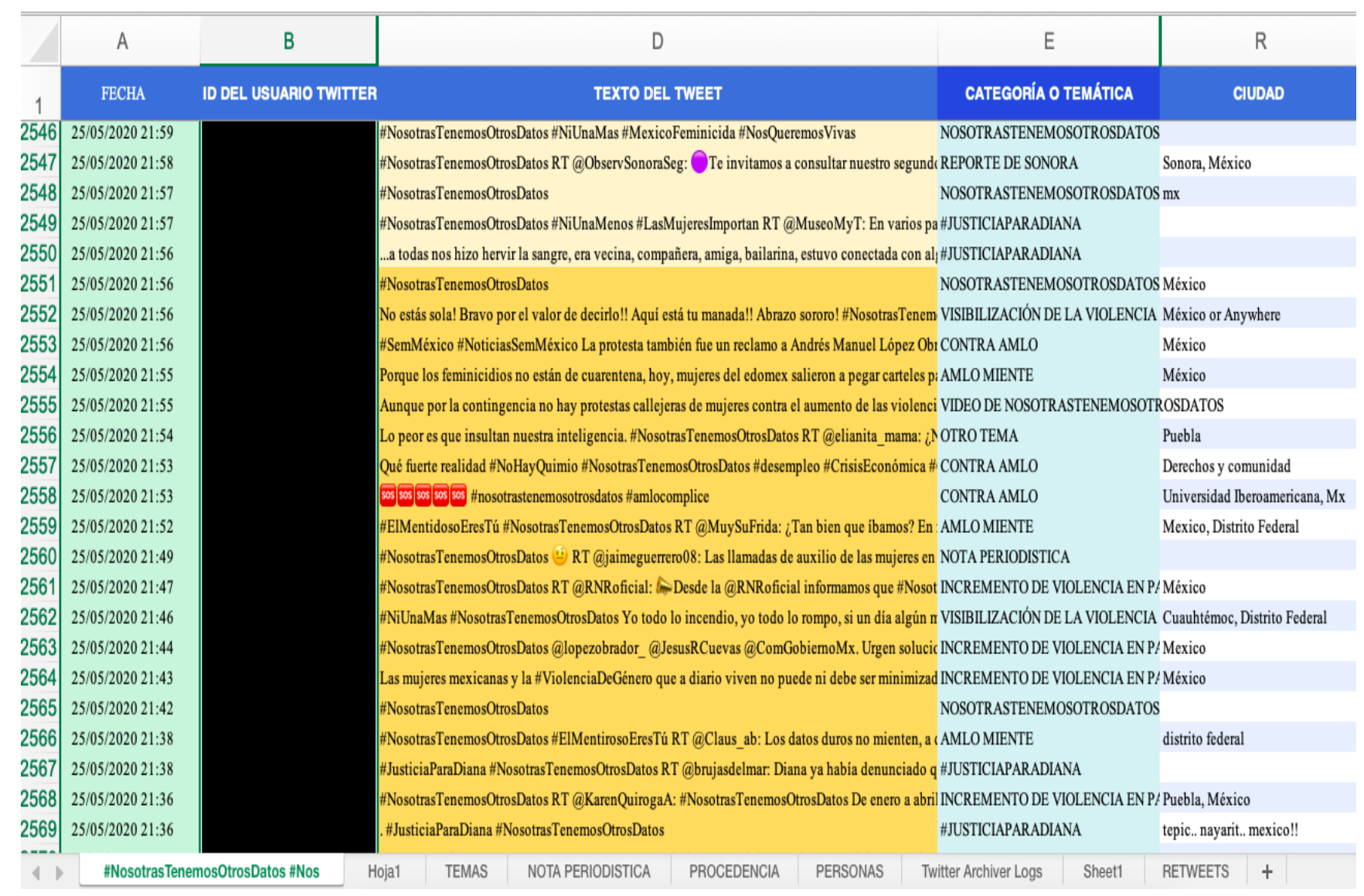

Nota. La columna de categoría o temática fue creada con el fin de determinar la temática del contenido del tuit. 


\section{Resultados}

El primer registro que se contabilizó fue el número de tuits por mes, teniendo como resultado del 6 al 31 mayo de 2020: 3,486 tuits (79\%), del 1 al 30 de junio de 2020: 1,278 tuits (25\%), y del 1 al 18 de julio de 2020: 236 tuits (5\%). El mayor concentrado de tuits fue publicado en el mes de mayo, que es cuando se origina la colectiva feminista \#NosotrasTenemosOtrosDatos, tal como se expone en el Gráfico 1.

En un segundo momento, en el corpus total de los 5,000 tuits recolectados se identificaron al menos 30 temáticas distintas (Gráfico 2). Entre las principales temáticas en donde se utilizó el hashtag \#NosotrasTenemosOtrosDatos fueron: 1) Promoción del hashtag \#NosotrasTenemosOtrosDatos: 662 tuits (13\%); 2) AMLO miente: 626 tuits (13\%); 3)

Visibilización de la violencia: 568 tuits $(11 \%) ; 4)$
Uso del hashtag \#JusticiaPara...: 356 tuits (7\%); 5) Sin relación al tema: 342 tuits $(7 \%)$; 6) Nota periodística: 309 tuits (6\%); 7) Conversatorios del colectivo \#NosotrasTenemosOtrosDatos: 302 tuits $(6 \%)$.

La principal temática de tuits está relacionada con la promoción del hashtag \#NosotrasTenemosOtrosDatos, donde se hace un llamado urgente al presidente Andrés Manuel López Obrador, al poder legislativo y judicial, medios de comunicación y opinión pública para visibilizar, prevenir y atender la violencia contra las mujeres. Esta campaña enfatizó su cuestionamiento sobre la ausencia de políticas públicas para atender la violencia contra las mujeres, promocionó un video que realizó la colectiva feminista Nosotros Tenemos Otros Datos, e invitó a sumarse y publicar una foto con el uso del hashtag \#NosotrasTenemosOtrosDatos.

\section{Gráfico 1}

Número de tuits por mes usando el hashtag: \#NosotrasTenemosOtrosDatos

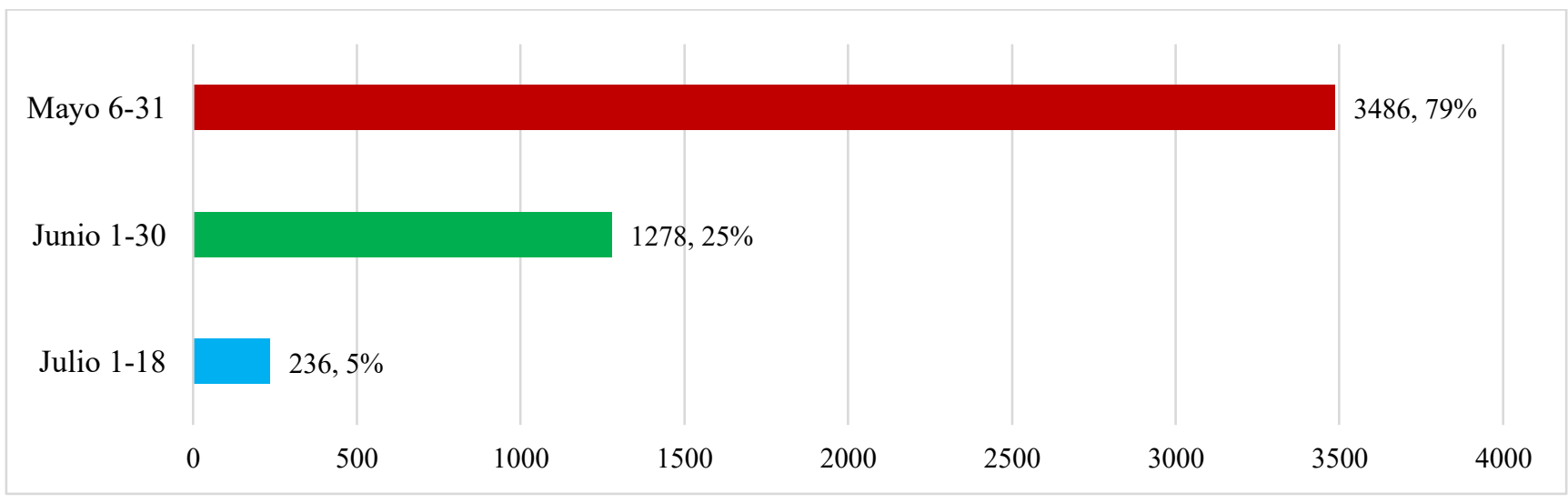




\section{Gráfico 2}

Temáticas de los tuits publicados con el hashtag \#NosotrasTenemosOtrosDatos

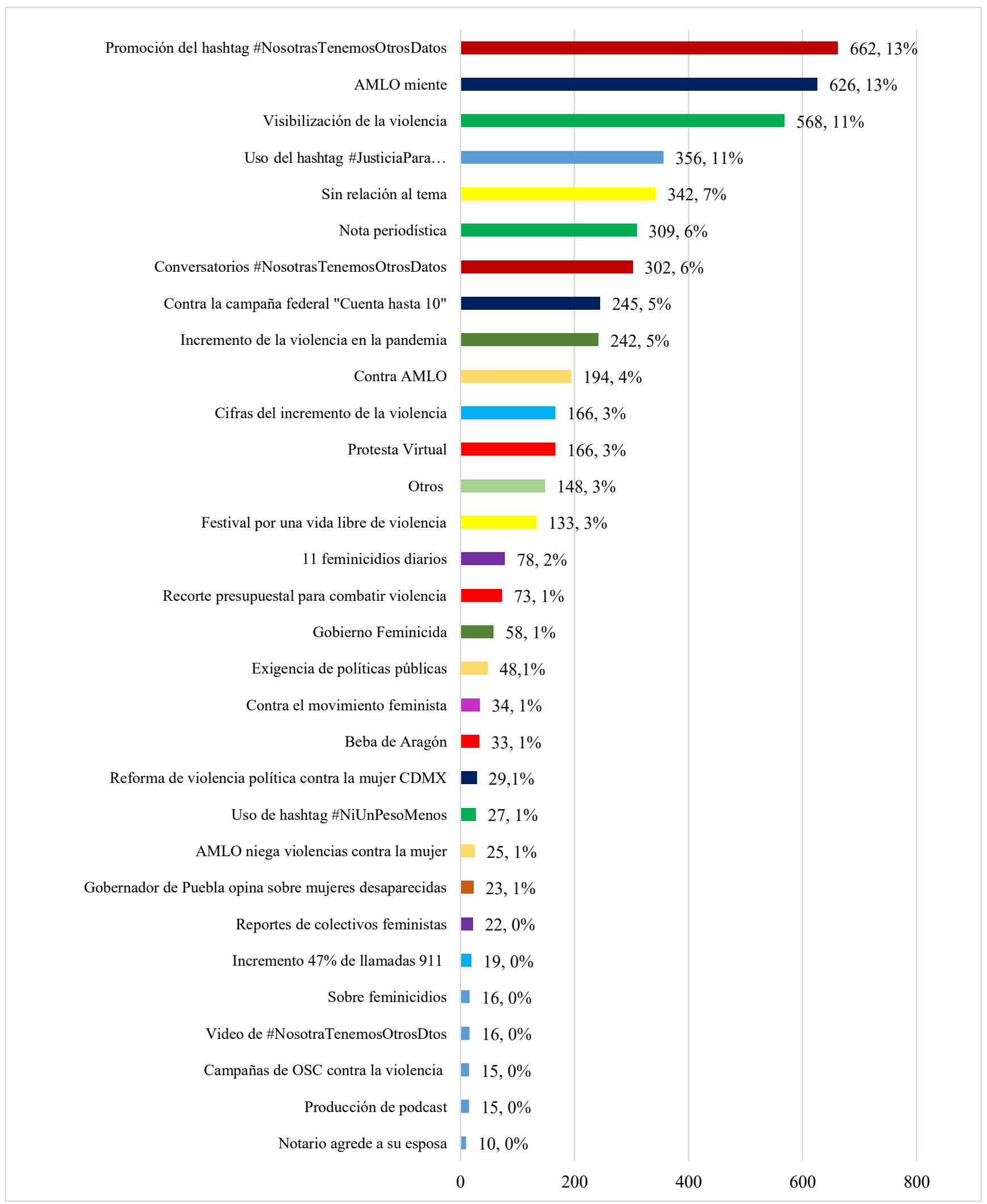


En la segunda temática de tuits, referida a "AMLO miente", se contextualiza este enunciado con leyendas como: "11 mujeres son asesinadas al día en México"; “AMLO negó completamente en la mañanera el recorte presupuestal para atención a mujeres víctimas de la violencia"; "la oficina presidencial tendría que poder respaldar los dichos del presidente"; y "basta de invisibilizar a las mujeres"; así como con el uso complementario de hashtags como \#ElMentirosoEresTú o \#MientesPresidente.

\section{Gráfico 3}

Principales tuiteras(os) que usaron el hashtag \#NosotrasTenemosOtrosDatos

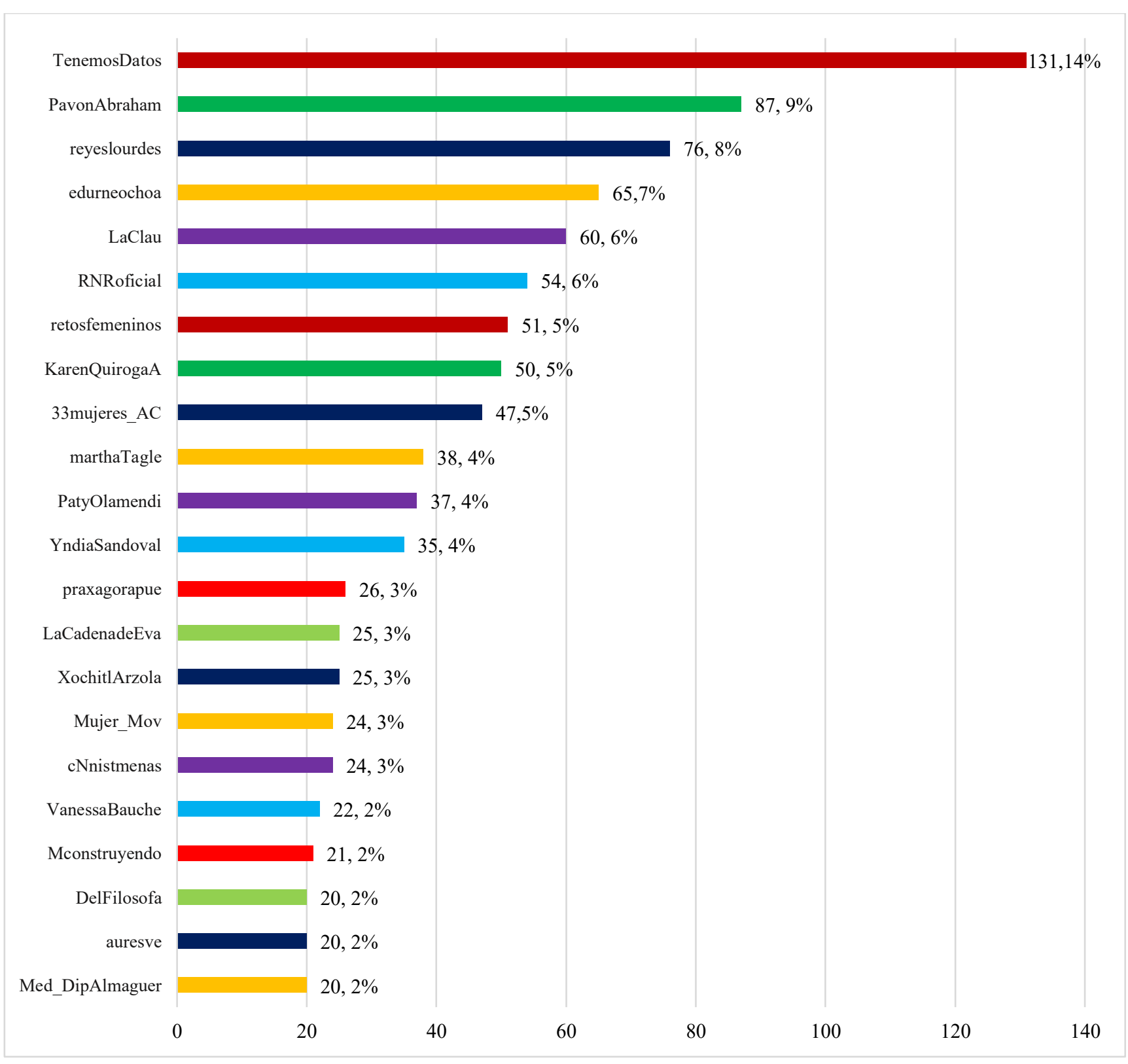


La tercera temática de tuits gira en torno a la "visibilización de la violencia", donde se informa que el año 2020 fue el más violento para niñas, adolescentes y mujeres en México a nivel nacional desde 2015. El confinamiento forzoso para evitar la propagación del coronavirus se ha convertido en caldo de cultivo de otro virus de efectos devastadores: la violencia machista, expresiones como "no nos sentimos seguras"; "el Estado debe garantizar la vida de las mujeres y es fundamental que las Instituciones implementen su trabajo", "las mujeres no están muriendo por el contagio de la COVID-19, sino por la violencia machista y feminicida; dentro de sus hogares, a manos de sus parejas y familiares"; y "la pandemia de la COVID19 ha reflejado las brecha de desigualdad que enfrentan las mujeres, quienes están más expuestas y son más afectadas económicamente". Algunos de los hashtags complementarios en esta temática son \#CuarentenaSinViolencia, \#NosQueremosSeguras, \#NiUnaMenos y \#NosEstanMatando.

En tercer lugar, se identificaron las principales tuiteras(os) que publicaron tuits utilizando el hashtag \#NosotrasTenemosOtrosDatos, tomando como mínimo 20 tuits publicados (Gráfico 3). Los ID de usuario que más tuitearon fueron: 1) @TenemosDatos (colectiva Feminista): 131 tuits (14\%); 2) @PavonAbraham (tuitero): 87 tuits (9\%); 3) @ reyeslourdes (actriz): 76 tuits (8\%); 4) @edurneochoa (activista feminista): 65 tuits (7\%); 5) @LaClau (activista feminista): 60 tuits $(6 \%) ; 6)$ @RNRoficial (OSC): 54 tuits (6\%).

De todo este universo de actores políticos se identificó que $41 \%$ son activistas feministas, $23 \%$ son tuiteros (sexo masculino), 18\% son colectivas feministas y $18 \%$, otros. En el Gráfico 3 observamos la presencia de tuiteras y tuiteros que, a través de sus tuits publicados, potencialmente pueden generar una polarización política y no estar genuinamente en pro de la defensa para la erradicación de la violencia contra las mujeres.

En cuarto lugar, identificamos las principales tuiteras y tuiteros que más re-tuits tuvieron (Gráfica 4), encontrando los siguientes resultados: 1) Lydia Cacho (periodista): 2577 re-tuits (22\%); 2) Denisse Dresser (periodista): 2380 re-tuits (21\%); 3) Red Nacional de Refugios (OSC): 1124 retuits (10\%); 4) Lourdes Mendoza (periodista): 822 re-tuits $(7 \%)$.

Los grupos con mayor influencia para el retuit de mensajes se concentran en los periodistas $(23 \%)$ y las OSC's (23\%), en un segundo lugar colectivas feministas (18\%), y en tercer lugar tuiteras y tuiteros $18 \%$. En este sentido, es importante mencionar que la presencia de figuras feministas mediáticas como es el caso de la periodista y activista feminista Lydia Cacho y Denise Dresser tienen una influencia en el espacio digital como en la plataforma digital de Twitter; sus mensajes tienen un efecto desproporcionadamente mayor que una tuitera o tuitero con pocos seguidores. Por ejemplo, Lydia Cacho, cuenta con más de 1 millón 400 mil seguidores y, en el caso de la académica y periodista Denise Dresser, cuenta con 4 millones 300 mil seguidores, lo que potencializó significativamente la viralización de sus publicaciones en la plataforma de Twitter con relación a la protesta digital feminista \#NosotrasTenemosOtrosDatos. 


\section{Gráfico 4}

Principales tuiteras (os) con más re-tuits que emplearon el hashtag \#NosotrasTenemosOtrosDatos

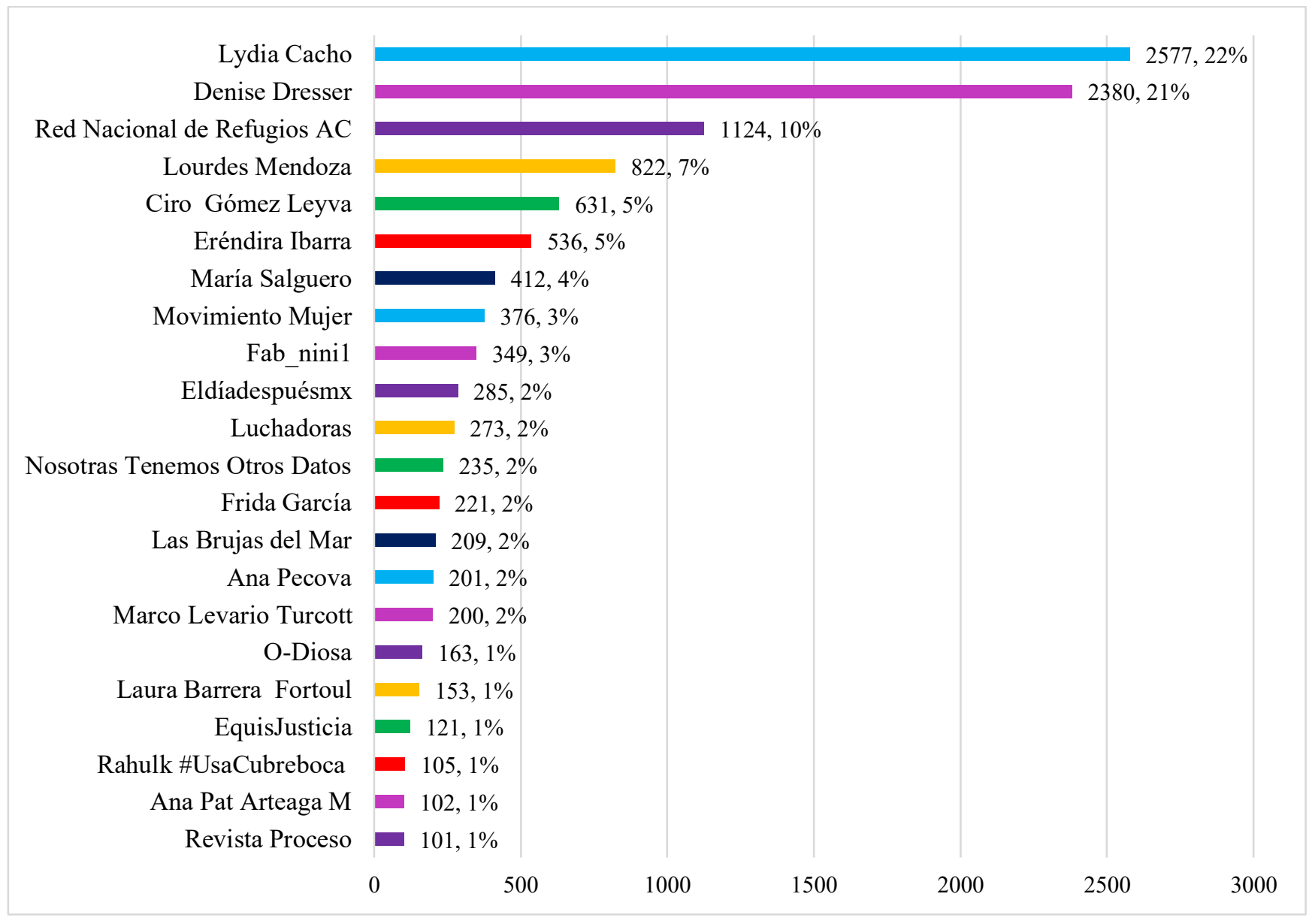

En quinto lugar, las principales temáticas re-tuiteadas y número de re-tuits que emplearon el hashtag \#NosotrasTenemosOtrosDatosVideo fueron $\left.\begin{array}{llll}\text { Gráfico } & 5\end{array}\right)$ : $\quad$ 1) $\quad \mathrm{El} \quad$ hashtag \#NosotrasTenemosOtrosDatos: 2608 tuits (23\%); 2) AMLO niega violencias: 2100 tuits $(18 \%) ; 3)$ " 10 feminicidios diarios": 1900 tuits (16\%); 4) Contra las mujeres de la 4T: 822 tuits $(7 \%) ; 5)$ “Contra campaña cuenta hasta 10": 810 tuits (7\%); 6) Manifestación virtual: 772 tuits (7\%); el término manifestación virtual, fue definido por la colectiva Nosotras Tenemos Otros Datos en el contexto de la pandemia de la COVID-19 como repertorios de acción colectiva en línea que convocan, por ejemplo, a subir fotos, carteles y/o videos sobre la realidad de la violencia contra las mujeres y niñas, exigiendo a las instituciones del Estado Mexicano que cumplan con su responsabilidad de promover, respetar, garantizar, defender y proteger los derechos humanos de las mujeres, usando el hashtag (NTOD, 2020c).

En el Gráfico 5 podemos observar que el video de la colectiva feminista "Nosotras Tenemos Otros Datos", fue el tuit que obtuvo más re-tuits, esto indica que el mensaje lanzado mediante el video fue 
el que mayor viralidad y presencia adquirió dentro de la protesta digital en Twitter, que en un primer momento vislumbró como intención contrarrestar la narrativa del presidente Andrés Manuel López Obrador ante la negación del incremento de la violencia contra las mujeres en la pandemia por la COVID-19. Sin embargo, en un segundo lugar, el hecho de que el presidente AMLO negara lo antes mencionado fue el tuit más re-tuiteado, lo que muestra que esta protesta digital se enmarca en una demanda ante el gobierno federal por la situación de emergencia que viven las mujeres en México y las trágicas cifras del aumento del feminicidio, así como las diversas violencias que afectan a miles de mujeres en el país.

En sexto lugar, las notas periodísticas de periódicos digitales y medios digitales difundidos en los tuits con el hashtag \#NosotrasTenemosOtrosDatos (Gráfico 6) fueron: 1) Otros: 137 tuits (44\%); 2) La Silla Rota: 27 tuits (9\%); 3) El Universal: 24 tuits (8\%); 4) Animal Político: 19 tuits $(6 \%)$.

\section{Gráfico 5}

Principales temáticas re-tuiteadas que emplearon el hashtag \#NosotrasTenemosOtrosDatos

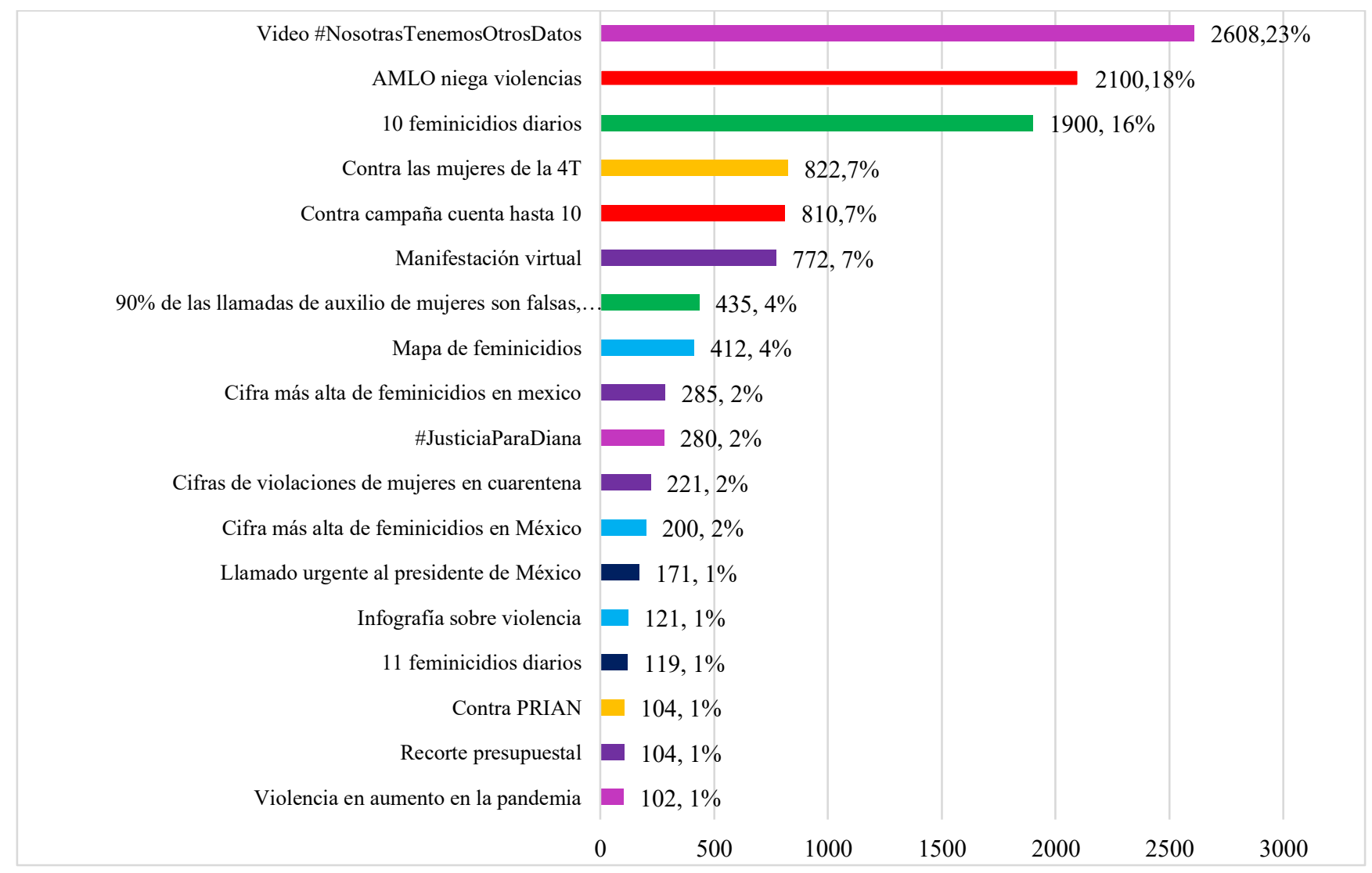


En el Gráfico 6 podemos observar una diversidad de medios digitales que publicaron notas periodísticas con relación a la protesta feminista digital de \#NosotrasTenemosOtrosDatos; sin embargo, se publicaron notas periodísticas que tienen relación con acontecimientos como feminicidios, cifras de la violencia contra las mujeres y diversas problemáticas relacionadas con el fenómeno en México. Es importante mencionar que del universo de tuits analizados (5,000 tuits), contabilizamos 313 notas periodísticas, lo que representa un $6.26 \%$ de todos los tuits publicados.
En séptimo lugar, las temáticas de las notas periodísticas tuiteadas empleando el hashtag \#NosotrasTenemosOtrosDatos fueron (Gráfico 7): 1) Incremento de violencia contra las mujeres: 46 tuits $(15 \%)$; 2) Nota sobre feminicidio: 44 tuits (14\%); 3) Crítica a AMLO ante la negación de la violencia de género: 29 tuits $(9 \%)$; 4) Otros: 29 tuits $(9 \%) ; 5)$ Manifestación virtual por el derecho de las mujeres a tener una vida libre de violencia: 23 tuits $(7 \%) ; 6)$ Violencia de género: 21 tuits (7\%); 7) Lanzamiento de \#NosotrasTenemosOtrosDatos: 19 tuits $(6 \%)$.

\section{Gráfico 6}

Notas periodísticas de periódicos digitales y medios digitales difundidos en los tuits con el hashtag \#NosotrasTenemosOtrosDatos

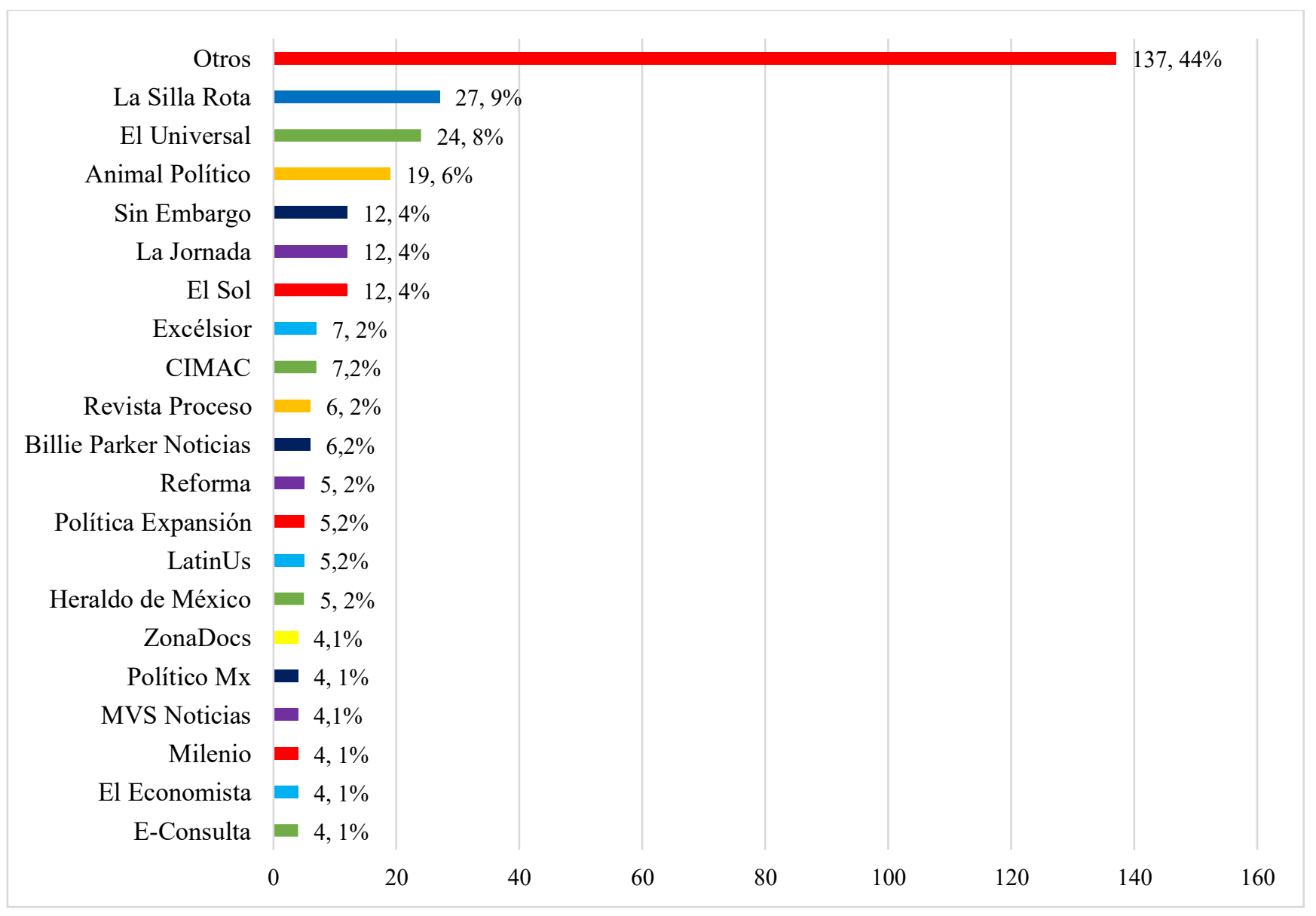




\section{Gráfico 7}

Temáticas de las notas periodísticas tuiteadas empleando el hashtag \#NosotrasTenemosOtrosDatos

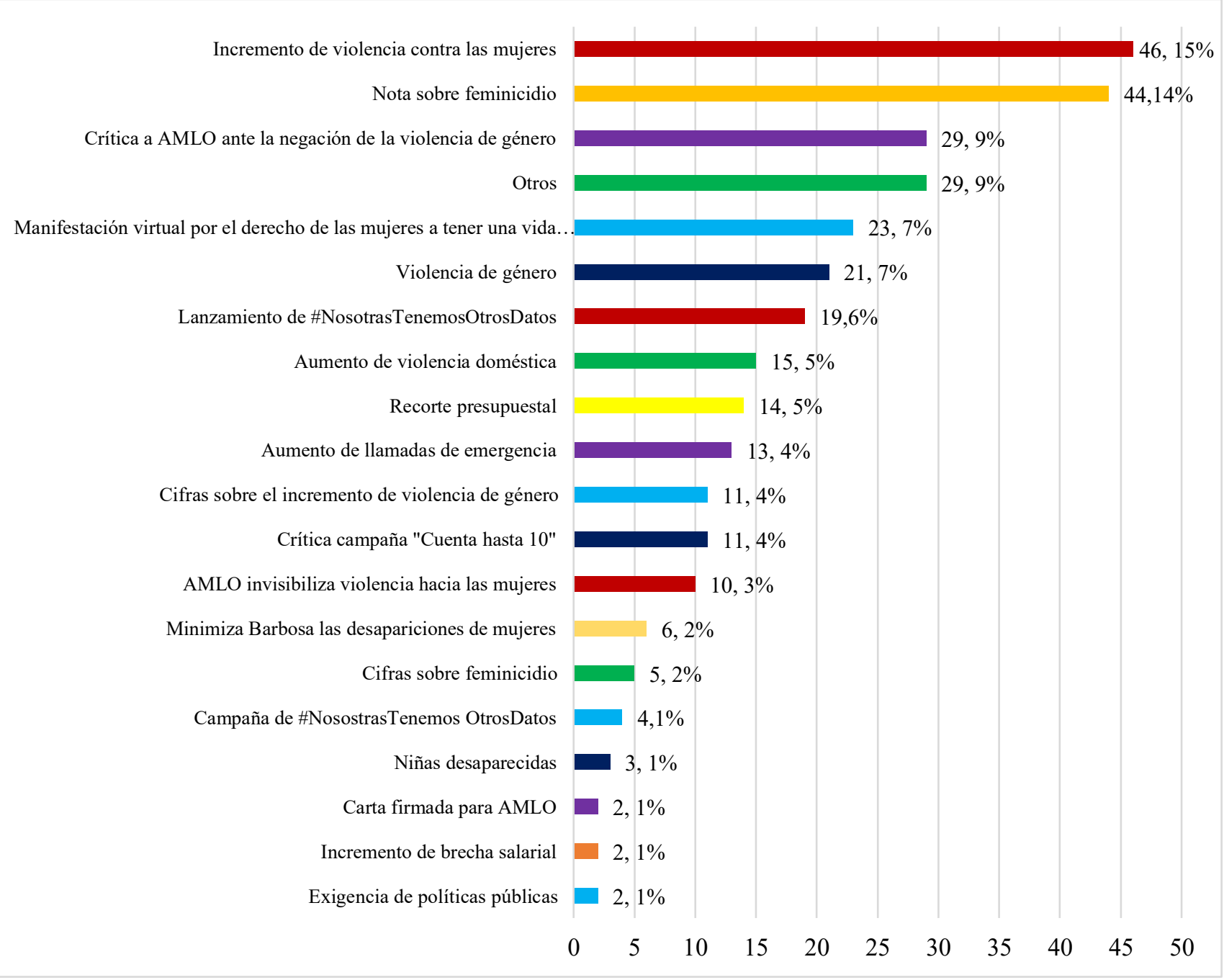

El Gráfico 7 presenta que el tema central de la producción de notas periodísticas se centró en la visibilización del incremento de la violencia contra las mujeres. En primer lugar, este dato denota una concordancia con el encuadre que la colectiva feminista \#NosotrasTenemosOtrosDatos, irrumpe en el espacio digital de Twitter ante la negativa del ejecutivo federal sobre el incremento de las cifras de violencia contra las mujeres. En segundo lugar, las notas periodísticas sobre feminicidio fueron utilizadas con el uso del hashtag \#NosotrasTenemosOtrosDatos para dar cuenta de los diversos feminicidios ocurridos durante de la pandemia por la COVID-19. Finalmente, en una tercera posición, la producción de notas periodísticas fijó su postura de realizar una crítica al ejecutivo federal por la negación del incremento de las cifras de violencia contra las mujeres en el confinamiento derivado de la pandemia. 


\section{Discusiones y conclusiones}

Respecto a la creación del hashtag \#NosotrasTenemosOtrosDatos de la red de organizaciones feministas Nosotras Tenemos Otros Datos, junto con la circulación del video en las redes sociodigitales titulado: "Presidente López Obrador, Nosotras Tenemos Otros Datos" (NTOD, 2020b), el presente trabajo -que comprendió un corpus de 5,000 tuits analizados del 6 de mayo al 18 de julio de 2020 - encontró que el pico de mayor actividad del hashtag \#NosotrasTenemosOtrosDatos en Twitter fue durante el mes de mayo, con un $79 \%$ del total del corpus analizado (3,486 tuits).

Las principales temáticas de los tuits fueron la promoción del hashtag \#NosotrasTenemosOtrosDatos a través de la plataforma social de Twitter, AMLO miente, y la visibilización de la violencia contra las mujeres; lo que indica que la protesta digital feminista queda enmarcada primordialmente en oposición al discurso del presidente Andrés Manuel López Obrador, así como a la atención de la problemática de violencia contra las mujeres en el confinamiento de la pandemia de la COVID-19.

Es a partir de la incursión de la colectiva feminista Nosotras Tenemos Otros Datos en el espacio digital de Twitter que se crea un ejemplo significativo de resistencia digital contra el discurso del presidente Andrés Manuel López Obrador, ante la negación del incremento de la violencia contra las mujeres que se visibilizó en las redes sociodigitales -principalmente en Twitter-, logrando viralizar temas y la circulación de noticias que no tenían visibilidad en los medios de comunicación tradicionales y dejando ver que la pandemia no obstaculizó el movimiento feminista sino que la fuerza del movimiento se mantiene activa. Asimismo, la protesta digital feminista, no se vio disminuida en su habilidad de criticar las acciones y omisiones de la actual administración que prometía una transformación y mayor respeto a los derechos humanos de toda la población. En consecuencia, ante la sociedad red y mediante las redes sociodigitales, se da paso al proceso de auto-comunicación autónoma que habilitó la diversidad de relatos en la esfera de lo digital, lejos del control de los medios tradicionales.

Para Magaña García (2019), las ventajas que tienen estos movimientos feministas permiten la creación de redes más horizontales, caracterizadas por su pluralidad y diversidad, haciendo posible su visibilidad tanto en su búsqueda de justicia como en la agenda política de género. Sin embargo, a raíz del presente estudio, podemos observar que las actoras y actores que más fuerza en convertir un tuit en un fenómeno viral son: periodistas, activistas feministas reconocidas dentro del ámbito político en la defensa de los derechos de las mujeres, y la misma colectiva feminista que dio origen al hashtag \#NosotrasTenemosOtrosDatos, es decir, prevalece una jerarquía grupal en cuanto a las y los agentes que pueden diseminar con más impacto viral entre usuarias y usuarios un mensaje de Twitter relacionado a la protesta digital.

Como dato emergente, las principales ciudades de procedencia de las tuiteras y tuiteros son 
Ciudad de México, Puebla y Jalisco. En este aspecto, podemos observar que la protesta digital feminista se enmarca como una acción colectiva en redes sociodigitales de tipo urbano, dado que sabemos de la existencia de descentralización de la protesta en zonas conurbadas, por ejemplo, el sureste de la Ciudad de México y el oriente del Estado de México, en donde el pasado 8 de marzo de 2021, las jóvenes feministas reivindicaron los conceptos de la periferia mediante la descentralización y optaron por organizar manifestaciones que recorrieron los sitios y espacios públicos donde ellas viven (Guerrero, 2021).

El mayor número de re-tuits provinieron de dos periodistas y una OSC, siendo que las temáticas más re-tuiteadas fueron el video de Nosotras Tenemos Otros Datos, AMLO niega violencia contra las mujeres, y "10 feminicidios diarios en México". Estos datos son muy similares a los anteriormente expuestos en relación a las principales temáticas de tuits publicados, donde se puede apreciar que la comunicación de la colectiva feminista Nosotros Tenemos Otros Datos, queda en primer lugar para dar a conocer su protesta digital, ante el discurso de negación del incremento de violencia contra las mujeres por parte del ejecutivo nacional y las alarmantes cifras de feminicidios diarios.

El impacto de la conversación digital a partir del uso del hashtag \#NosotrasTenemosOtrosDatos fue tal que tuvo repercusiones en la agenda mediática y en Twitter. Las principales notas periodísticas de medios digitales en donde se asoció al hashtag provinieron de La Silla Rota, El Universal, y Animal Político; y los temas de las notas periodísticas fueron el incremento de la violencia contra las mujeres, el feminicidio, y la crítica a AMLO ante la negación de la violencia contra las mujeres. Estos datos presentan una similitud con los resultados antes expuestos, sobre las temáticas de los tuis más publicados y los re-tuits más viralizados, lo que dio más fuerza a la comunicación y viralización del hashtag \#NosotrasTenemosOtrosDatos. Los medios de comunicación desempeñan un papel fundamental para la acción colectiva porque proporcionan un contexto que puede influir y moldear la opinión pública; por esta razón, la cantidad de atención mediática puede tener un impacto en el éxito de una acción de protesta. (Della Porta, 2011).

Por parte de los medios digitales, a partir de la publicación de notas periodísticas por Twitter utilizando el hashtag \#NosotrasTenemosOtrosDatos, el tema se encuadra de igual modo en la visibilización de la violencia contra las mujeres, mediante las notas periodísticas sobre los feminicidios y el incremento de esta, así como notas periodísticas relacionadas a la crítica hacia el presidente de México, por negar la violencia contra las mujeres. En este sentido, lo que podemos afirmar es la reciente emergencia de un periodismo con perspectiva de género como lo es La Cadera de Eva del grupo La Silla Rota, que es una compañía de comunicación multimedia, lo que da paso a un periodismo con una narrativa desde una perspectiva de género, a partir de esta sección.

Las redes sociodigitales incorporan nuevas miradas y formas de análisis que alimenten a otras expresiones de comunicación, lo que hace que se conformen como un actor y agente dentro de las 
protestas digitales feministas, como lo fue en el caso del activismo hashtag feminista \#NosotrasTenemosOtrosDatos. Otro de los temas centrales con relación a la violencia contra las mujeres mediante los re-tuits publicados se refiere a la visibilización de la violencia de género a través del tuit relacionado con "10 feminicidios diarios en México" y el incremento de la violencia hacia las mujeres durante el confinamiento por la pandemia de la COVID-19.

Un hallazgo relevante en la presente investigación es la presencia de tuiteras y tuiteros como actores políticos con fines partidistas que se insertan dentro de la protesta digital de \#NosotrasTenemosOtrosDatos, potencializando la polarización digital. Este elemento es un componente más dentro del activismo digital feminista en una diversa ecología de redes sociodigitales, en donde los repertorios de acción colectiva quedan insertos en un entramado de variados actores sociales en la búsqueda del cambio social para erradicar la violencia contra las mujeres. Sin embargo, encontramos escasa información sobre el fenómeno de la polarización digital en torno a las recientes protestas digitales feministas en México, por lo que sugerimos, en tal sentido, una línea de investigación en futuros estudios para responder a la pregunta: $¿$ De qué manera influyen los diversos actores de la protesta feminista digital en las redes sociodigitales en la polarización de las demandas para la erradicación de la violencia contra las mujeres?

Uno de los principales aportes de este estudio en relación al activismo digital feminista en el contexto de la pandemia por COVID-19 ha sido observar la manera audaz y creativa por parte de las mujeres activistas para reconfigurar un activismo feminista digital con estrategias comunicativas que ofrecen los servicios de las redes sociodigitales y que han permitido otro tipo de repertorios de acción enmarcados en la protesta feminista digital, como los son la realización de conversatorios en línea y debates que se transmiten en vivo en Facebook, relacionados a las problemáticas de violencia contra las mujeres, así como la creación de hashtags es que han podido organizar con objetivos comunes y captar un notable control del propio discurso, esto es de la voz e imagen de los distintos movimientos de mujeres, y tener más agencia para la conformación de la propia identidad (Pfleger, 2021); en este caso de estudio, para denunciar el discurso gubernamental que estigmatiza la protesta feminista e invisibiliza las causas estructurales de la violencia contra las mujeres.

A pesar de todas las desventajas, limitaciones e implicaciones negativas que ha enfrentado la protesta feminista durante la pandemia de la COVID-19, existen redes que están impulsando una respuesta sin precedentes en este contexto, desde intervenciones políticas multilaterales hasta acciones solidarias en barrios urbanos de bajos ingresos; habilidades, técnicas y conexiones a largo plazo han permitido a las feministas, dentro y fuera de los gobiernos, ejercer rápidamente presión sobre las y los responsables políticos nacionales e internacionales. En este sentido, la protesta digital feminista ha sido una parte muy importante para contrarrestar a las autoridades en la exigencia de una agenda política con perspectiva de género que 
atienda estas problemáticas acentuadas durante el confinamiento por la contingencia sanitaria. Finalmente, mediante la protesta digital feminista \#NosotrasTenemosOtrosDatos, logró irrumpir en las redes sociodigitales como Twitter, teniendo impacto en los medios digitales, y contrarrestar así la invisibilización en el discurso oficial del ejecutivo nacional ante la negación del incremento de las violencias contra las mujeres durante el confinamiento de la pandemia por la COVID-19.

\section{Agradecimientos}

Agradezco al Consejo Nacional de Ciencia y Tecnología (CONACYT) por su apoyo para la Estancia Posdoctoral por México 2021 y al Sistema Nacional de Investigadores (SNI), que se realiza en la Universidad de Guanajuato, bajo la asesoría de la Dra. Ericka López Sánchez en la Maestría de Análisis Político del Departamento de Estudios Políticos y Gobierno.

\section{Referencias bibliográficas}

Abramowitz, A., \& Saunders, K. (2008). Is polarization a myth? The Journal of Politics, 70(2), 542-555. https://doi.org/10.1017/s0022381608080493

Álvarez Enríquez, L. (2020). El movimiento feminista en México en el siglo XXI: juventud, radicalidad y violencia. Revista mexicana de ciencias políticas y sociales, 65(240), 147-175. https://doi.org/10.22201/fcpys.2448492xe.2020.240.76388

Badillo, D. (2020, May 3). Aumentan agresiones contra mujeres durante confinamiento. El Economista. https://bit.ly/3zS2KW5

Bakshy, E., Messing, S., \& Adamic, L. A. (2015). Exposure to ideologically diverse news and opinion on Facebook. Science, 348(6239), 1130-1132. https://doi.org/10.1126/science.aaa1160

Bardin, L. (2002). El análisis de contenido (Trad. C. Suarez, 3a Ed.). Ediciones Akal. (Trabajo original publicado en 1977).

Bernárdez Rodal, A., López Priego, N., \& Padilla Castillo, G. (2021). Cultura y movilización social contra la violencia sexual a través de Twitter: el caso del fallo judicial "\#LaManada" en España. Revista Latina de Comunicación Social, (79), 237-262. https://doi.org/10.4185/RLCS-2021-1502

Binder, I. (2019). Identidad y agencia colectiva del movimiento ciberfeminista en América Latina. El caso de ciberfeministaslatam. Revista DÍGITOS, (5), 210-233. http://dx.doi.org/10.7203/rd.v0i5.128

Castells, M. (2012). Networks of outrage and hope social movements in the internet age. Polity Press.

Centro de Producción de Programas Informativos y Especiales (2020a, February 17). Conferencia de prensa del 17 de febrero de 2020 [Video]. https://bit.ly/3F71IIh

Global Media Journal México, 18(35), 71-94, julio - diciembre 2021. 
Centro de Producción de Programas Informativos y Especiales (2020b, May 6). Conferencia de prensa del 6 de mayo de 2020 [Video]. https://bit.ly/3yFfyiw

Cerva Cerna, D. (2020). La protesta feminista en México. La misoginia en el discurso institucional y en las redes sociodigitales. Revista Mexicana de Ciencias Políticas y Sociales, 65(240), 177-205. http://dx.doi.org/10.22201/fcpys.2448492xe.2020.240.76434

Cerva Cerna, D. (2021). Criminalización de la protesta feminista: el caso de las colectivas de jóvenes estudiantes en México. Investigaciones Feministas, 12(1), 115-125. https://doi.org/10.5209/infe.69469

Clark-Parsons, R. (2019). "I SEE YOU, I BELIEVE YOU, I STAND WITH YOU”: \#MeToo and the performance of networked feminist visibility. Feminist Media Studies, 21(3), 362-380. https://doi.org/10.1080/14680777.2019.1628797

Della Porta, D. (2011). Communication in movement: Social movements as agents of participatory democracy. Information, Communication \& Society, 14(6), 800-819. https://doi.org/10.1080/1369118X.2011.560954

Etling, B., Faris, R., \& Palfrey, J. (2010). Political change in the digital age: The fragility and promise of online organizing. SAIS Review, 30(2), 37-49. https://bit.ly/3DZSyNr

Guerrero, C. (2021, March 10). \#8M descentralizado. Pie de Página. https://bit.ly/3yTi1of

Hetherington, M. (2001). resurgent mass partisanship: The role of elite polarization. The American Political Science Review, 95(3), 619-631. https://doi.org/10.1017/S0003055401003045

Howard, P., \& Hussain, M. (2010). Digital media and the Arab Spring. NSF-PAR Public Access Repository. https://bit.ly/3tsIzf2

Jasso, C. (2020, February 25) Contrastes en el PAN: tomaron la bandera del feminismo con fuerza, pero promueven leyes anti-aborto Infobae. https://bit.ly/2Vlgt8C

Krippendorff, K. (1980). Content analysis: An introduction to its methodology. Sage.

Krippendorff, K. (1982, May). Paradox and information [Presentación en papel]. International Communication Association, Boston, Massachusettes, Estados Unidos.

Loader, B. \& Mercea, D. (2011). Networking democracy? Social media innovations and participatory politics. Information, $\quad$ Communication $\quad \& \quad$ Society, 14(6), 757-769. https://doi.org/10.1080/1369118X.2011.592648

López, F. (2002). El análisis de contenido como método de investigación. XXI, Revista de Educación, 4, 167-179. https://bit.ly/3BRZ4UC

Mattoni, A., Berdnikovs, A., Ardizzoni M. \& Cox L. (2010) Voices of dissent: activists' engagements in the creation of alternative, autonomous, radical and independent media. Interface: A Journal for and about Social Movements, 2(2), 1-22 https://bit.ly/3E5Bhl3

Magaña García, C. (2019). Un balance de las agendas sociales latinoamericanas, las mujeres y los gobiernos progresistas. Controversias y Concurrencias Latinoamericanas, 11(19), 157-167. https://bit.ly/2WZDtLv

Global Media Journal México, 18(35), 71-94, julio - diciembre 2021. 
Mendes, K., Ringrose, J., \& Keller, J. (2019) Digital feminist activism: girls and women fight back against rape culture. Oxford University Press.

Milenio (2020, March 24). Conferencia matutina de AMLO, 24 de marzo de 2020 [Video]. https://bit.ly/3slA5HU Muñoz-Saavedra, J. (2019). Una nueva ola de feminista... más allá de \#MeToo. Irrupción, legado y desafíos. En P. Rivera-Vargas, J. Muñoz-Saavedra, R. Morales Olivares y S. Butendieck-Hijerra (Eds.). Políticas Públicas para la Equidad vol. II. [Preprint], Colección Políticas Públicas. Universidad de Santiago de Chile.

Nosotras Tenemos Otros Datos (2020a). Informe Alterno CEDAW 2020. https://bit.ly/3z2Z0j8

Nosotras Tenemos Otros Datos. (2020b, May 11). Presidente López Obrador, Nosotras Tenemos Otros Datos [Video]. https://bit.ly/3J6uzyE

Nosotras Tenemos Otros Datos (2020c, May 22). ¡Atención! este 25 de mayo a partir de las 11am iniciaremos la Manifestación Virtual por el Derechos de las Mujeres [Status update with photographs]. Facebook. https://bit.ly/3yDRxbO

Pedraza Bucio, C. I., \& Rodríguez Cano, C. A. (2019). Resistencias sumergidas. Cartografía de la tecnopolítica feminista en México. Teknokultura. Revista de Cultura Digital y Movimientos Sociales, 16(2), 197-212. https://doi.org/10.5209/tekn.64163

Pfleger, S. (2021). Fuertes, libres, rebeldes. Hacia una identidad más agentiva del movimiento feminista en México. Millcayac - Revista Digital De Ciencias Sociales, 8(14), 325-348. https://doi.org/10.48162/rev.33.015

Piñeiro-Otero, T. (2021). 'Escúchanos, hermana'. Los podcasts como prácticas y canales del activismo feminista. Revista Inclusiones, 8(Especial), 231-254. https://bit.ly/3hih1Uz

Poell, T., \& Borra, E. (2012). Twitter, YouTube, and Flickr as platforms of alternative journalism: The social media account of the 2010 Toronto G20 protests. Journalism, 13(6),695713. https://doi.org/10.1177/1464884911431533

Puente, S., Maceiras, S. D., \& Romero, D. F. (2021). Twitter activism and ethical witnessing: Possibilities and challenges of feminist politics against gender-based violence. Social Science Computer Review, 39(2), 295-311. https://doi.org/10.1177/0894439319864898

Revilla Blanco, M. (2019). Del ¡Ni una más! al \#NiUnaMenos: movimientos de mujeres y feminismos en América Latina. Política y Sociedad, 56(1), 47-67. https://doi.org/10.5209/poso.60792

Reyes, Y. (2020, May 12). 7 mil mujeres entregarán carta de reclamo a AMLO por minimizar la violencia de género. Reporte Índigo. https://bit.ly/3yTi4jV

Salazar Méndez, A. (2020, September 29). Recortan el 75\% del presupuesto al Inmujeres. El Financiero. https://bit.ly/38WCLAI

Global Media Journal México, 18(35), 71-94, julio - diciembre 2021. 
Secretariado Ejecutivo del Sistema Nacional de Seguridad Pública (2020, July 31). Información sobre violencia contra las mujeres. Incidencia delictiva y llamadas de emergencia 9-1-1. https://bit.ly/3zTTwIT

Sunstein C. (2002). The law of group polarization. The Journal of Political Philosophy, 10(2), 175-197. https://doi.org/10.1111/1467-9760.00148

Theocharis, Y., Barberá, P., Fazekas, Z., \& Popa, S. A. (2020). The Dynamics of Political Incivility on Twitter. SAGE Open. https://doi.org/10.1177/2158244020919447

Van Laer, J. (2007). Internet use and protest participation: how do ICTs affect mobilization? Working paper PSWpaper 2007/1. Antwerp: Politieke Wetenschappen. https://bit.ly/3jSOIQc

Villar Aguilés, A., \& Pecourt Gracia, J. (2021). Antifeminismo y troleo de género en Twitter. Estudio de la subcultura trol a través de \#STOPfeminazis. Teknokultura. Revista de Cultura Digital y Movimientos Sociales, 18(1), 33-44. https://doi.org/10.5209/tekn.70225

Xantomila J. (2020, May 12). Más de 6 mil firmas lleva carta dirigida a AMLO por violencia de género. La Jornada. https://bit.ly/2YBdmuH 